\title{
Intersectional insights from an MDMA-assisted psychotherapy training trial: An open letter to racial/ethnic and sexual/gender minorities
}

\author{
TERENCE H. W. CHING*
}

Department of Psychological Sciences, University of Connecticut, Storrs, CT, USA

(Received: April 17, 2019; accepted: June 13, 2019)

\begin{abstract}
The road to the current psychedelic renaissance in research on $\pm 3,4$-methylenedioxymethamphetamine (MDMA) the active ingredient of the drug Ecstasy - for addressing treatment-resistant post-traumatic stress disorder has been fraught with political and academic bias, as well as cultural stigma among underserved populations, all of which serve as barriers to minority inclusion and participation. In this open letter to ethnic/racial and sexual/gender minorities, the author details intersectional insights from his own experience being administered MDMA legally as part of a therapist training trial for MDMA-assisted psychotherapy, in hopes of radically destigmatizing this treatment approach for marginalized populations. Themes covered include: set and setting; cultural pride; LGBTQIA+ pride; acceptance of intersectionality; and patience, perspective, and strength in retrospection. This letter concludes by tasking current investigators of MDMA-assisted psychotherapy to emphasize issues of intersecting identities (e.g., in terms of race, ethnicity, sexual orientation, and gender identity) in their research agenda, attempt to improve minority participation in a culturally attuned manner, as well as increase minority stakeholdership in this field.
\end{abstract}

Keywords: MDMA, psychedelics, psychotherapy, sexual identity, race, ethnicity

\section{INTRODUCTION}

\pm 3 ,4-Methylenedioxymethamphetamine (MDMA), the active ingredient of the street drug Ecstasy, was studied initially as an adjunct psychotherapeutic tool, prior to its nationwide prohibition. It was first termed "Adam," to represent its ability to lower one's defenses while enhancing primal connectedness to others, and was used by therapists to treat a wide range of psychiatric conditions (Grob, 2000). With the recent resurgence of interest in, and evidence of, its psychotherapeutic potential, MDMA currently exists in the American consciousness with polarized perceptions.

On one hand, MDMA remains a Drug Enforcement Agency (DEA)-classified Schedule I illicit substance (i.e., highest abuse potential, no known medical benefits, and strictly prohibited outside of research settings, with highest penalties for recreational/illegal use; United States Drug Enforcement Agency, 2018). The path to its current Schedule I status was notoriously fraught with political bias. Initial enthusiasm over its unique entactogenic/empathogenic properties and therapeutic potential was overshadowed by large-scale drug trafficking, hedonistic marketing, politically manipulated media sensationalism, and cultivation of an overall climate of exaggerated fears about MDMA's threats to public health and safety (Grob, 2000; King \& Corkery, 2010). After MDMA was scheduled, academic articles similarly perpetuated misinformation about the neurocognitive effects of MDMA, particularly in the United States (for detailed critiques, see Amoroso, 2016; Doblin et al., 2014). Pursuing psychedelic therapy research thus becomes an arduous process, due to obstacles such as uninformed institutions and colleagues who view these medicines as dangerous and lacking in observable medical benefits (Barnett, Siu, \& Pope, 2018; Nutt, King, \& Nichols, 2013; Sessa, 2017).

On the other hand, MDMA is the pharmacological component of MDMA-assisted psychotherapy, an FDAdesignated "breakthrough therapy" for treatment-resistant posttraumatic stress disorder (PTSD; Burge, 2017). This treatment is currently being tested in Phase 3 trials sponsored by the Multidisciplinary Association for Psychedelic Studies (MAPS), with multiple sites optioned across the United States. These trials are seeking to replicate previous findings of high and sustained rates of PTSD symptom recovery, as well as overall drug safety and secondary gains (e.g., improved depressive symptoms and reduced substance use; Bouso, Doblin, Farre, Alcazar, \& Gómez-Jarabo, 2008; Mithoefer et al., 2013, 2018; Mithoefer, Wagner, Mithoefer, Jerome, \& Doblin, 2010; Ot'alora et al., 2018).

\section{Stressors and PTSD in marginalized communities}

Despite the psychedelic-assisted psychotherapy renaissance, the PTSD literature highlights several existing and urgent public health issues. A DSM-5 (American Psychiatric Association, 2013) diagnosis of PTSD may be made when there is an identifiable "Criterion A" index trauma, such as combat or assault. However, certain experiences outside of the Criterion A umbrella can still cause a traumatic reaction

* Corresponding address: Terence H. W. Ching, MSocSci; Department of Psychological Sciences, University of Connecticut, 406 Babbidge Road, Unit 1020, Storrs, CT 06269, USA; Phone: +1 860486 2642; Fax: +1 860486 4848; E-mail: terence.ching@ uconn.edu

This is an open-access article distributed under the terms of the Creative Commons Attribution-NonCommercial 4.0 International License, which permits unrestricted use, distribution, and reproduction in any medium for non-commercial purposes, provided the original author and source are credited, a link to the CC License is provided, and changes - if any - are indicated. 
and can potentially exacerbate an individual's ability to cope with and recover from conventional Criterion A events (e.g., Williams \& Leins, 2016). These non-Criterion A stressors include exposure to racist acts (i.e., racial trauma) and additional forms of oppression based on, or at the intersection(s) with, gender, sexuality, and other stigmatized identities (Chae, Lincoln, \& Jackson, 2011; Ching, Lee, Chen, So, \& Williams, 2018; Holmes, Facemire, \& Da Fonseca, 2016; Pieterse, Carter, Evans, \& Walter, 2010; Williams et al., 2014; Williams, Kanter, \& Ching, 2018; Williams, Peña, \& Mier-Chairez, 2017). For example, sexual/gender minorities of color are at risk of experiencing structural stressors such as homophobia or transphobia in their ethnic communities, as well as racism in the lesbian, gay, bisexual, transgender, queer, intersex, and asexual+ (LGBTQIA+) community (for an intersectional conceptual model, see Ching et al., 2018). In addition, the racist War on Drugs has resulted in African Americans being disproportionately charged with drug-related offenses, despite equivalent rates of use and possession as Whites (Cooper, 2015).

As a result, the prevalence and expression of PTSD symptoms also vary by race/ethnicity and sexual/gender identity in the United States. Indigenous peoples, as well as Black and Latinx individuals, may be at increased risk of PTSD, compared with non-Hispanic Whites (Alegría et al., 2013; Hall-Clark, Sawyer, Golik, \& Asnaani, 2016; Kisely et al., 2017; Roberts, Gilman, Breslau, Breslau, \& Koenen, 2011). Additionally, compared with non-Hispanic Whites, African Americans with PTSD may view the world as more threatening but demonstrate less heightened arousal (Williams, Jayawickreme, Sposato, \& Foa, 2012). Furthermore, sexual minority and transgender individuals experience higher rates of PTSD than their heterosexual and cisgender counterparts, respectively (Roberts, Austin, Corliss, Vandermorris, \& Koenen, 2010; Shipherd, Maguen, Skidmore, \& Abramovitz, 2011). This may be mediated by the internalization of stigma. According to minority stress theory (Meyer, 2003), internalized homophobia/transphobia is predictive of various forms of psychopathology, including PTSD symptoms, psychological distress, and substance abuse (Puckett \& Levitt, 2015; Puckett, Mereish, Levitt, Horne, \& Hayes-Skelton, 2018; Straub, McConnell, \& Messman-Moore, 2018).

\section{Barriers to minority inclusion}

The aforementioned public health disparities have not been adequately addressed. The enrollment of diverse participants in MDMA-assisted psychotherapy trials has been poor (Michaels, Purdon, Collins, \& Williams, 2018). In fact, only $9.5 \%$ of participants who completed the study in the six Phase 2 trials were ethnoracial minorities (Mithoefer et al., 2019). Additionally, based on anecdotal knowledge, no information on sexual orientation has been collected. There are multiple explanations for this disparity. First, there tends to be a general lack of emphasis on increasing minority representation, both in terms of potential participants, as well as the investigators who conduct such research (Williams, 2018). As such, recruitment methods are typically ineffective and culturally insensitive (Williams, Reed, \& Aggarwal, in press). Strong cultural barriers also exist in the recruitment of people of color in such research, especially given the racialized sociopolitical history of illicit drug use and medical research in the United States (e.g., the atrocities conducted during the Tuskegee Syphilis Study; Katz et al., 2006). This has led to stigmatizing cultural perceptions of psychedelic drug use as risky, dangerous, and indicative of a sexually deviant lifestyle (Rigg, 2017; Rigg \& Lawental, 2018), as well as mistrust of psychopharmacological and medical research in general (Harris, Gorelick, Samuels, \& Bempong, 1996; Suite, La Bril, Primm, \& Harrison-Ross, 2007). Penalties at the state and federal levels for possession of Schedule I substances, including exorbitant fines, and imprisonment ranging from a few months to decades, often further fuel stigma related to accessing psychedelic substances in pursuit of mental wellness. As such, most people from disenfranchised and marginalized communities steer clear of MDMA-assisted psychotherapy, even when suffering from chronic and intractable PTSD. Furthermore, because extant research has yet to examine whether and how psychedelic therapy can be useful in addressing the unique intersectional stressors that individuals with multiple stigmatized identities experience, these individuals may feel excluded altogether from potential benefits offered by the psychedelic renaissance.

In the following, I narrate key experiences and insights from being administered MDMA legally as part of a therapist training trial for MDMA-assisted psychotherapy for PTSD in hopes of destigmatizing and piquing interest in this treatment approach for researchers and potential participants/patients alike (ClinicalTrials.gov identifier: NCT01404754). Because these insights draw on my intersectional lived experiences as an immigrant, an ethnoracial minority individual, and member and ally of the LGBTQIA+ community, I especially invite readers from these communities to approach the following material with openness and curiosity, and to imagine parallel possibilities for recovering from minority stress and trauma.

\section{SET AND SETTING}

In the psychedelic-assisted psychotherapy arena, the influences of set and setting on the quality of psychedelic experiences have been emphasized. These concepts refer to important non-drug factors (e.g., life histories, mindset, intention/motivations, and environmental factors accompanying psychedelic use such as the location of use, music, etc.) that can shape the effects of the intended psychedelic substance (Hartogsohn, 2016, 2017). As such, it is important to consider my cultural background and personal life history, as components of set, which have led up to my participation in the trial.

In its 50-odd years of independence, my home country Singapore has grown to be a global hub for excellence and innovation in education, healthcare, finance, technology, tourism, and trade. English is the lingua franca, with three other official languages: Mandarin Chinese, Bahasa Melayu, and Tamil. The country is also extremely religiously, racially, and culturally diverse, with racial harmony being an integral part of the nation's constitution and national policies. Despite these progressive aspirations, the nation has clung onto archaic laws, including the criminalization of 
mutually consensual sex between adult men. Furthermore, in Singapore, the Misuse of Drugs Act classifies MDMA into Class A, akin to Schedule I in the US. The statute allows for presumption of trafficking for the threshold amount of $10 \mathrm{~g}$, accompanied by penalties that include long-term imprisonment, caning, and even capital punishment (i.e., execution by the state) at higher amounts (typically, 10 times the trafficking threshold; Attorney-General's Chambers, 2019). Ironically, $10 \mathrm{~g}$ (or $100 \mathrm{~g}$ ) of MDMA equates to a full course of treatment for 16 (or 160) individuals with PTSD, as per the MAPS-sponsored protocol (Mithoefer, 2016). In a way, growing up as a sexual minority in a staunchly heteronormative Singaporean society has paradoxically created an inevitable drive in me to defy social conventions, in order to buffer against structural propaganda that criminalizes an unchangeable aspect of my identity. This also translated to, I believe, curiosity about what it might be like to take MDMA (similarly, a criminalized substance), albeit legally, in the therapist training trial.

Given the prospect of participating in this trial, I had set the intention of delving deeper into dissonance I felt about various parts of my identity (i.e., my immigrant, ethnoracial, and sexual minority statuses). Nonetheless, I experienced some hesitation for various reasons. This was my first time opening up about chronic, highly personal, minority identityrelated stressors in great detail to unfamiliar therapeutic professionals in a formal setting. These stressors included past experiences of homophobic microaggressions (Cyrus, 2017) and painful invalidation by others in my ethnic community upon disclosure, which naturally made the fear of rejection extremely salient. This also evoked the cultural and familial values of "saving face" and not "airing one's dirty laundry" (i.e., discussing "shameful" personal information with others outside of the family; Lim, 2016; Yang \& Kleinman, 2008). I had wondered, "Do my therapists know about these stressors? Will they be able to empathize, since they are neither Chinese Singaporean nor gay? If not, will I be left to work these issues through on my own in a highly vulnerable state? Will this be retraumatizing for me, to not receive support for my sexual identity once again?" It was helpful, given earlier psychoeducational components of the training, that I had acquired knowledge to help somewhat assuage these concerns. The consistent message was that MDMA facilitates a somewhat courageous revisiting of traumatic events in one's past without feeling overwhelmed by typical emotions of fear and anxiety (Mithoefer, 2016). Knowing this, and hearing it presented again by my therapists in the initial preparatory session, helped create an appropriate mindset going into the first dosing session. I was also reassured during this session by my therapists' sensitivity and unquestioning belief in the validity of my experiences. Not once did I feel forced to discuss my issues any more than I desired. In fact, I believe that the male-female, husband-wife, parental figure-like composition of the therapy team facilitated a highly compassionate, candid, and ultimately, corrective interaction in regard to the discussion of my sexuality [I write this in recognition of queer critiques of the hegemonic nature of heteronormative families (e.g., Allen \& Mendez, 2018); while the presence of different-gender therapists provided a corrective experience when it came to disclosure of my sexuality-related issues, other people might benefit more from having same-gender therapists for various reasons (e.g., feeling more safe or comfortable with a non-heteronormative therapy team)]. There was also an indescribable experience of being "seen" and "heard" as a queer person of color in a White heteronormative society simply by having an older female therapist of color sitting patiently across the room, conveying acceptance, nurturance, and in a sense, nonjudgmental "permission" to open up about my issues.

I give a lot of credit to my therapists in facilitating a holistically safe and healing environment (i.e., setting) for me once I got to Colorado. I was set up in the home of a close colleague who catered to my every basic need. I was also assigned a male night attendant after my dosing session to care for and monitor me. The therapists and night attendant were available at all times to talk about anything and everything, and to even transport me personally to and from the clinic. I felt cared for, and most of all, deserving of care in this entire process. I think this in itself can be an extremely powerful and persuasive part of the healing process, especially for traumatized individuals, to know that their care is not limited to within the therapy room, but rather, extends to other settings in their healing process. In fact, the predominant sentiment at the end of my visits with my therapists was that they were "masters of their craft," to have facilitated such a transformative first experience with MDMA-assisted psychotherapy for me.

On the day of the MDMA dosing session, I entered a clinic in Boulder, CO, USA. Expertly curated playlists, eyeshades, headphones, flowers, a lit candle, cushions, pillows, and blankets were provided for my experience. Taking the first pill offered in a ceremonial cup, I immersed myself in the initiation drumming music. The MDMA took effect, invoking an out-of-body observation of arms reaching out from within myself, forming a cocoon for the rest of my psychedelic journey. With the help of my two therapists in a supportive and healing setting, I experienced the following visions during my dosing session, which has led to insights that have evolved from the integration session leading up to the time of this writing. It is important to note that these visions and imagery, although highly idiosyncratic, have led to insights, which I believe might plausibly extend to others with similar identities.

\section{CULTURAL PRIDE}

\section{Experiences}

Recurrently, during the dosing session, I would encounter a tapir - an endangered animal native to the jungles of Southeast Asia and the forests of South and Central America - traipsing toward, away, and alongside me in a vast desert, as if lost and searching for a place to rest. Coming face-to-face with the tapir, the statement resonated within me, "He's in the wrong place, and needs to be back in the jungle where he can find water, survive, and thrive." Elsewhere, I chanced upon a giant Rafflesia arnoldii, a nearly extinct plant native to Southeast Asia that produces the world's largest individual flower. It is better known as 
the "corpse flower," due to its pungent odor reminiscent of decaying flesh. I was not deterred; I hopped into the opening at its core, dancing among the pollen.

\section{Insights}

The tapir, as a symbol of my Southeast Asian heritage, showed me that it is important to remember my cultural roots, to never forsake and abandon my cultural identity, especially while attempting to navigate this foreign land (USA) where I currently reside. My dance within the core of the $R$. arnoldii was, again, symbolic of unabashedly embracing my cultural origins, including the "strangest" and most "alien" aspects, at least to the Western eye. I realized that these fauna and flora, as proxies for my cultural identity, are unique and endangered, and deserve to be protected and cherished. These visions highlighted the continual challenge of decolonizing internalized racism in predominantly White spaces that most people of color face in mainstream American society. These visions also conveyed preemptive strategies to combat internalized racism: accurate recognition that shame about one's "other-ness" has been the result of structural racism as opposed to actual inferiority, as well as self- and collective affirmation of various aspects of one's cultural background (including unique customs and practices) as instrumental in cultivating strong ethnic pride.

\section{LGBTQIA+ PRIDE}

\section{Experiences}

During my dosing session, I also witnessed fantastical fusions and vivid variations of organisms. Early on in my journey, my closed-eye visuals took shape and formed a neon purple hedgehog, which emanated a soft glow from within my chest, emerging occasionally as my spirit animal guide while I traversed landscapes. Thereafter, I encountered a giant horseshoe crab in the middle of the ocean, which grew the fin of a mermaid's tail on its back, shimmering iridescent colors off its scales that dispersed throughout the undercurrents. In these rainbow-like displays, I could see into, and beyond, the gradations of the light spectrum, realizing that there are no hard boundaries, just seamless transitions between hues, each one unique and special.

\section{Insights}

While an obvious cue to my queerness, these visions are testament to the vibrancy and diversity of the LGBTQIA+ community, reminding me to look beyond the stereotypical constraints or labels that society has placed on my sexual identity (i.e., "no hard boundaries"), and deeper into my unique lived experiences as a sexual minority (i.e., "each one unique and special"). I have since grown to appreciate the beauty and uniqueness of my sexual identity in the context of my cultural background. Most importantly, these visions have inspired the deep realization that the journey to accepting my sexuality does not need to conform to prescribed norms, which include the Western notion of "coming out" to one's friends and family in a declarative fashion. Owing to strong stigma against non-heteronormative orientations where I come from (and perhaps in most immigrant families and communities of color), sexual identity development can often be a prolonged process of subtle ebbs and flows in terms of concealment and "out-ness" (Huang, Chen, \& Ponterotto, 2016; Kimmel \& Yi, 2004). Understanding both the variable timeframe and nature of this process can be beneficial, at least in alleviating the fear and anxiety that surround the illusion that one needs to disclose one's sexual orientation, often dramatically, as a necessary rite of passage.

\section{ACCEPTANCE OF INTERSECTIONALITY}

\section{Experiences}

During the peak of my journey in the dosing session, on a vast green plain, galloping toward me, I encountered another chimera, a hybrid animal with the head, body, and legs of a horse, attached by the tail to a crocodile. The two parts were fighting; the crocodile thrashed about and snapped at the hooves of the horse, while the horse kicked back with its hind legs, visibly agitated. I thought to myself, "They need to figure out how to coexist together, no matter how incompatible!" Periodically, the conflict would cease. The horse would slow to a stop and graze, while the crocodile would curl forward onto the back of the horse, basking in the sun. Each would be at peace with the other, until they started up again. This cycle continued for another three iterations until I found myself drawn closer to the creature, attempting to soothe it. Spontaneously, the chimera dissolved into a full-length mirror. Stepping up, I saw my reflection in the mirror, and witnessed the emergence, from within my chest, the Chinese characters for fire and wood represented in their elemental images. These characters slowly overlapped, magically not burning each other out.

\section{Insights}

These experiences had a lasting impact on my psychology, holding the mirror (literally) up to the chronic internal conflicts of allegiances I experienced in relation to my ethnic community (which I cherish but which also prohibits same-sex relationships) and membership within the LGBTQIA+ community (which can be racist against members of color; Sarno, Mohr, Jackson, \& Fassinger, 2015). Intersectional stress and trauma is real and debilitating among Asian sexual/gender minorities, and the reason for their chronicity stems arguably from attempting to navigate oppressive environments that do not acknowledge and accept all parts of one's intersectional identity. In a sobering manner, I came away from these experiences realizing that in order to rise above discrimination and internalized minority stress, I will need to radically accept the intersectional aspects of my ethnic and sexual identities, especially since this holistic form of acceptance may not be readily available in either community. Essentially, regardless of external validation, what matters is that I accept and affirm myself, even when it gets challenging to do so. 


\section{PATIENCE, PERSPECTIVE, AND STRENGTH IN RETROSPECTION}

Most of these revelations were not immediately obvious. I have learned to appreciate their subtle, allegorical nature. It took time -3 years and counting, at the time of this writing - to discover their underlying meanings, to "connect the dots," and integrate their messages into my being. MDMA catalyzes an openness to unravelling experiences and insights that continue to evolve over time with additional integration. Thus, it is obvious how this can be helpful in regard to the experience of trauma, which often creates guardedness, hypervigilance, and grossly distorted views about the post-traumatic self, world, and future.

In addition, I had the amazing opportunity to experience oscillations in size (from gigantic to microscopic) throughout my journey. I took this as encouragement to continually perceive challenges in a different light, to be able to take a step back from myopic focus on negativity and recognize and be grateful for the positive aspects of my daily existence.

Near the end of my journey, I saw a permanent afterglow in the sky in the desert and felt a warm internal serenity. A clock appeared in the sky showing the time 9:04 a.m., coinciding with the start of my psychedelic journey. I thought to myself, "Any time is MDMA time." I realized that I can always look back on this experience, and draw on my insights for strength. In fact, I have done so on different occasions since then to cope with new identity-related stressors, and have discovered a comforting internal resilience, being able to tolerate distress better, calm down quicker, reframe appraisals more deftly, and bounce back sooner than usual. Just as my insights continue to evolve over time, I remain open and optimistic about learning new lessons from new challenges in life.

\section{FINAL THOUGHTS}

I think "integrated" and "integrational" are apt words to describe my post-MDMA outlook on life. "Integrated," because of my own acceptance and affirmation of my intersectional identities, and "integrational," because I look forward to being open to new experiences as opportunities to further expand, cultivate, and assimilate into my unique personal identity. My experience with MDMA has strengthened my cultural identity and resilience in the face of subsequent racial stressors, which is consistent with the protective role of ethnic identity against the mental health effects of racial microaggressions in individuals of Asian descent (Choi, Lewis, Harwood, Mendenhall, \& Huntt, 2017; Rivas-Drake, Hughes, \& Way, 2008). My MDMA experience has also facilitated greater self-compassion and psychological flexibility, which have been especially helpful in terms of adapting to, easing, and coexisting with the chronic dissonance I felt between my sexual and ethnic identities while attempting to navigate my ethnic community and LGBTQIA+ spaces. Indeed, self-compassion and psychological flexibility have been shown to promote mental wellness in sexual minorities by ameliorate internalized homophobia (Beard, Eames, \& Withers, 2017; Matos, Carvalho, Cunha, Galhardo, \& Sepodes, 2017).
Nonetheless, I write from the privilege of having had a successful (and relatively unchallenging) dosing session, and rather fulfilling self- and other-guided integration experiences, as well as many privileged opportunities, such as the ability to peruse my own life goals. As such, I am cognizant that my particular combination of minority stressors and personal experience with MDMA-assisted psychotherapy might not be representative of those of other queer individuals of color, especially those in gravely disadvantaged circumstances or who may face greater social stigmas.

For example, transphobia elicits arguably different stressors compared to homophobia. The World Health Organization (WHO) only very recently reclassified gender dysphoria as a sexual health issue rather than a mental disorder in 2018 (WHO, 2019), while "homosexuality" has experienced a comparatively longer period of formal destigmatization since its declassification from the DSM in 1973 (Drescher, 2015). This meant that transgender individuals had to suffer tremendous, ongoing structural barriers in order to legitimize their gender identity (e.g., having to endure "mandatory" psychodiagnostic assessment of one's gender dysphoria before being able to pursue transitionrelated options, including hormone replacement therapy, or even changing one's gender label on government-issued identification cards). Thus, it is no wonder that rates of mental illness (e.g., depression, anxiety, and PTSD) tend to be elevated in transgender communities as opposed to cisgender or other communities (Shipherd et al., 2011). Therein lie questions about how well these concerns (especially when intersecting with issues of race/ethnicity, sexual orientation, etc.) can be discussed in an empathic manner in the preparatory, dosing, and integration sessions, and if not, whether this has undesired consequences, such as increased dropout, or worse yet, iatrogenic, retraumatizing effects.

These are questions that need to be addressed in future research, especially Phase 3 study sites for MDMA-assisted psychotherapy for PTSD, which are currently enrolling participants. However, we know that minority inclusion is low not only at the participant level; anecdotally, researchers, therapists, and administrative staff from marginalized backgrounds who are involved in any aspect of existing trials for MDMA-assisted psychotherapy are few and far in between (Williams, 2018). If people do not see individuals from their communities represented at the research/therapist/ administration levels in these trials, how likely are they to participate? As seen in my case, MDMA-assisted psychotherapy can catalyze a powerful meaning-making process in resolving internalized intersectional minority stress. Thus, I believe that it is important to increase minority stakeholdership in this field, in order to facilitate culturally attuned outreach efforts to underrepresented populations, as well as to steadfastly challenge problems of bias and stigma as a unified, mutually uplifting whole. To do that, issues of intersectionality need to be at the forefront of the MDMA-assisted psychotherapy research agenda, with the aim of examining how these issues can be addressed in this promising form of treatment.

Acknowledgements: The author would like to thank Marcela Ot'alora and Bruce Poulter for their therapeutic support 
and guidance in his experience. He would also like to thank the non-profit organization, Multidisciplinary Association of Psychedelic Studies (MAPS; www.maps.org), who sponsored and funded this Phase 1 study (i.e., A Phase 1 Placebo-Controlled, Double-Blind, Multi-Site Crossover Study to Assess Psychological Effects of MDMA when Administered to Healthy Volunteers; MT-1) (ClinicalTrials. gov identifier: NCT01404754).

Conflict of interest: The author declares no conflict of interest.

\section{REFERENCES}

Alegría, M., Fortuna, L. R., Lin, J. Y., Norris, F. H., Gao, S., Takeuchi, D. T., Jackson, J. S., Shrout, P. E., \& Valentine, A. (2013). Prevalence, risk, and correlates of posttraumatic stress disorder across ethnic and racial minority groups in the United States. Medical Care, 51(12), 1114-1123. doi:10.1097/ MLR.0000000000000007

Allen, S. H., \& Mendez, S. N. (2018). Hegemonic heteronormativity: Toward a new era of queer family theory. Journal of Family Theory \& Review, 10(1), 70-86. doi:10.1111/jftr. 1224110.1111/jftr.12241

American Psychiatric Association. (2013). Diagnostic and statistical manual of mental disorders: DSM-5. Washington, DC: American Psychiatric Association.

Amoroso, T. (2016). Ecstasy research: Will increasing observational data aid our understanding of MDMA? The Lancet Psychiatry, 3(12), 1101-1102. doi:10.1016/S2215-0366(16)30345-5

Attorney-General's Chambers. (2019, April 9). Misuse of Drugs Act, Part III: Evidence, enforcement, and punishment. Retrieved from https://sso.agc.gov.sg/Act/MDA1973\#P1III-

Barnett, B. S., Siu, W. O., \& Pope, H. G., Jr. (2018). A survey of American psychiatrists' attitudes toward classic hallucinogens. Journal of Nervous and Mental Disease, 206(6), 476-480. doi:10.1097/NMD.0000000000000828

Beard, K., Eames, C., \& Withers, P. (2017). The role of selfcompassion in the well-being of self-identifying gay men. Journal of Gay \& Lesbian Mental Health, 21(1), 77-96. doi:10.1080/19359705.2016.1233163

Bouso, J. C., Doblin, R., Farre, M., Alcazar, M. A., \& GómezJarabo, G. (2008). MDMA-assisted psychotherapy using low doses in a small sample of women with chronic posttraumatic stress disorder. Journal of Psychoactive Drugs, 40(3), 225-236. doi:10.1080/02791072.2008.10400637

Burge, B. (2017, August 26). FDA grants breakthrough therapy designation for MDMA-assisted psychotherapy for PTSD, agrees on special protocol assessment for phase 3 trials. Retrieved from https://maps.org/news/ media/6786-press-release-fda-grants-breakthrough-therapydesignation-for-mdma-assisted-psychotherapy-for-ptsd-agreeson-special-protocol-assessment-for-phase-3-trials

Chae, D. H., Lincoln, K. D., \& Jackson, J. S. (2011). Discrimination, attribution, and racial group identification: Implications for psychological distress among Black Americans in the National Survey of American Life (2001-2003). American Journal of Orthopsychiatry, 81(4), 498-506. doi:10.1111/j. 1939-0025.2011.01122.x
Ching, T. H. W., Lee, S. Y., Chen, J., So, R. P., \& Williams, M. T. (2018). A model of intersectional stress and trauma in Asian American sexual and gender minorities. Psychology of Violence, 8(6), 657-668. doi:10.1037/vio0000204

Choi, S., Lewis, J. A., Harwood, S., Mendenhall, R., \& Huntt, M. B. (2017). Is ethnic identity a buffer? Exploring the relations between racial microaggressions and depressive symptoms among Asian-American individuals. Journal of Ethnic \& Cultural Diversity in Social Work, 26(1-2), 18-29. doi:10.1080/15313204.2016.1263815

Cooper, H. L. F. (2015). War on drugs policing and police brutality. Substance Use \& Misuse, 50(8-9), 1188-1194. doi:10.3109/10826084.2015.1007669

Cyrus, K. (2017). Multiple minorities as multiply marginalized: Applying the minority stress theory to LGBTQ people of color. Journal of Gay \& Lesbian Mental Health, 21(3), 194-202. doi:10.1080/19359705.2017.1320739

Doblin, R., Greer, G., Holland, J., Jerome, L., Mithoefer, M. C., \& Sessa, B. (2014). A reconsideration and response to Parrott AC (2013) "Human psychobiology of MDMA or 'Ecstasy': An overview of 25 years of empirical research". Human Psychopharmacology, 29(2), 105-108. doi:10.1002/hup.2389

Drescher, J. (2015). Out of DSM: Depathologizing homosexuality. Behavioral Sciences, 5(4), 565-575. doi:10.3390/bs5040565

Grob, C. S. (2000). Deconstructing ecstasy: The politics of MDMA research. Addiction Research, 8(6), 549-588. doi:10.3109/ 16066350008998989

Hall-Clark, B., Sawyer, B., Golik, A., \& Asnaani, A. (2016). Racial/ethnic differences in symptoms of posttraumatic stress disorder. Current Psychiatry Reviews, 12(2), 124-138. doi:10.2174/1573400512666160505150257

Harris, Y., Gorelick, P. H., Samuels, P., \& Bempong, I. (1996). Why African Americans may not be participating in clinical trials. Journal of the National Medical Association, 88, 630-634.

Hartogsohn, I. (2016). Set and setting, psychedelics and the placebo response: An extra-pharmacological perspective on psychopharmacology. Journal of Psychopharmacology, 30(12), 1259-1267. doi:10.1177/0269881116677852

Hartogsohn, I. (2017). Constructing drug effects: A history of set and setting. Drug Science, Policy, and Law, 3, 1-7. doi:10.1177/2050324516683325

Holmes, S. C., Facemire, V. C., \& Da Fonseca, A. M. (2016). Expanding Criterion A for posttraumatic stress disorder: Considering the deleterious impact of oppression. Traumatology, 22(4), 314-321. doi:10.1037/trm0000104

Huang, J., Chen, E. C., \& Ponterotto, J. G. (2016). Heterosexual Chinese Americans' experiences of their lesbian and gay sibling's coming out. Asian American Journal of Psychology, 7(3), 147-158. doi:10.1037/aap0000051

Katz, R. V., Kegeles, S. S., Kressin, N. R., Green, B. L., Wang, M. Q., James, S. A., \& Claudio, C. (2006). The Tuskegee legacy project: Willingness of minorities to participate in biomedical research. Journal of Health Care for the Poor and Underserved, 17(4), 698-715. doi:10.1353/hpu.2006.0126

Kimmel, D. C., \& Yi, H. (2004). Characteristics of gay, lesbian, and bisexual Asians, Asian Americans, and immigrants from Asia to the USA. Journal of Homosexuality, 47(2), 143-172. doi:10.1300/J082v47n02_09

King, L. A., \& Corkery, J. M. (2010). An index of fatal toxicity for drugs of misuse. Human Psychopharmacology, 25(2), 162-166. doi:10.1002/hup.1090 
Kisely, S., Alichniewicz, K. K., Black, E. B., Siskind, D., Spurling, G., \& Toombs, M. (2017). The prevalence of depression and anxiety disorders in indigenous people of the Americas: A systematic review and meta-analysis. Journal of Psychiatric Research, 84, 137-152. doi:10.1016/j.jpsychires.2016.09.032

Lim, J. Y. T. (2016). Faces of Singapore \& mediation. Contemporary Issues in Mediation, 1, 59-71. doi:10.1142/978981 3108370_0005

Matos, M., Carvalho, S. A., Cunha, M., Galhardo, A., \& Sepodes, C. (2017). Psychological flexibility and self-compassion in gay and heterosexual men: How they relate to childhood memories, shame, and depressive symptoms. Journal of LGBT Issues in Counseling, 11(2), 88-105. doi:10.1080/15538605.2017.1310007

Meyer, I. H. (2003). Prejudice, social stress, and mental health in lesbian, gay, and bisexual populations: Conceptual issues and research evidence. Psychological Bulletin, 129(5), 674-697. doi:10.1037/0033-2909.129.5.674

Michaels, T. I., Purdon, J., Collins, A., \& Williams, M. T. (2018). Inclusion of people of color in psychedelic assisted psychotherapy: A review of the literature. BMC Psychiatry, 18(1), 245. doi:10.1186/s12888-018-1824-6

Mithoefer, M. C. (2016). A manual for MDMA-assisted psychotherapy in the treatment of posttraumatic stress disorder (Vol. 8). Santa Cruz, CA: Multidisciplinary Association for Psychedelic Studies.

Mithoefer, M. C., Feduccia, A. A., Jerome, L., Mithoefer, A., Wagner, M., Walsh, Z., Hamilton, S., Yazar-Klosinski, B., Emerson, A., \& Doblin, R. (2019). MDMA-assisted psychotherapy for treatment of PTSD: Study design and rationale for phase 3 trials based on pooled analysis of six phase 2 randomized controlled trials. Psychopharmacology. Advance online publication. doi:10.1007/s00213-019-05249-5

Mithoefer, M. C., Mithoefer, A. T., Feduccia, A. A., Jerome, L., Wagner, M., Wymer, J., Holland, J., Hamilton, S., YazarKlosinski, B., Emerson, A., \& Doblin, R. (2018). 3, 4-Methylenedioxymethamphetamine (MDMA)-assisted psychotherapy for post-traumatic stress disorder in military veterans, firefighters, and police officers: A randomised, double-blind, dose-response, phase 2 clinical trial. The Lancet Psychiatry, 5(6), 486-497. doi:10.1016/S2215-0366(18)30135-4

Mithoefer, M., Wagner, M., Mithoefer, A., Jerome, L., \& Doblin, R. (2010). The safety and efficacy of \pm 3 , 4methylenedioxymethamphetamine-assisted psychotherapy in subjects with chronic, treatment-resistant posttraumatic stress disorder: The first randomized controlled pilot study. Journal of Psychopharmacology, 25(4), 439-452. doi:10.1177/026988 1110378371

Mithoefer, M., Wagner, M., Mithoefer, A., Jerome, L., Martin, S., Yazar-Klosinski, B., Michel, Y., Brewerton, T., \& Doblin, R. (2013). Durability of improvement in post-traumatic stress disorder symptoms and absence of harmful effects or drug dependency after 3, 4-methylenedioxymethamphetamineassisted psychotherapy: A prospective long-term follow-up study. Journal of Psychopharmacology, 27(1), 28-39. doi: $10.1177 / 0269881112456611$

Nutt, D. J., King, L. A., \& Nichols, D. E. (2013). Effects of Schedule I drug laws on neuroscience research and treatment innovation. Nature Reviews Neuroscience, 14(8), 577-585. doi:10.1038/nrn3530

Ot'alora, G. M., Grigsby, J., Poulter, B., Van Derveer, J. W., Giron, S. G., Jerome, L., Feduccia, A., Hamilton, S.,
Yazar-Klosinski, B., Emerson, A., Mithoefer, M., \& Doblin, R. (2018). 3, 4-Methylenedioxymethamphetamineassisted psychotherapy for treatment of chronic posttraumatic stress disorder: A randomized phase 2 controlled trial. Journal of Psychopharmacology, 32(12), 1295-1307. doi:10.1177/0269881118806297

Pieterse, A. L., Carter, R. T., Evans, S. A., \& Walter, R. A. (2010). An exploratory examination of the associations among racial and ethnic discrimination, racial climate, and trauma-related symptoms in a college student population. Journal of Counseling Psychology, 57(3), 255-263. doi:10.1037/a0020040

Puckett, J. A., \& Levitt, H. M. (2015). Internalized stigma within sexual and gender minorities: Change strategies and clinical implications. Journal of LGBT Issues in Counseling, 9(4), 329-349. doi:10.1080/15538605.2015.1112336

Puckett, J. A., Mereish, E. H., Levitt, H. M., Horne, S. G., \& Hayes-Skelton, S. A. (2018). Internalized heterosexism and psychological distress: The moderating effects of decentering. Stigma and Health, 3(1), 9-15. doi:10.1037/ sah0000065

Rigg, K. K. (2017). Motivations for using MDMA (ecstasy/molly) among African Americans: Implications for prevention and harm-reduction programs. Journal of Psychoactive Drugs, 49(3), 192-200. doi:10.1080/02791072.2017.1305518

Rigg, K. K., \& Lawental, M. (2018). Perceived risk associated with MDMA (ecstasy/molly) use among African Americans: What prevention and treatment providers should know. Substance Use \& Misuse, 53(7), 1076-1083. doi:10.1080/10826084. 2017.1392985

Rivas-Drake, D., Hughes, D., \& Way, N. (2008). A closer look at peer discrimination, ethnic identity, and psychological wellbeing among urban Chinese American sixth graders. Journal of Youth and Adolescence, 37(1), 12-21. doi:10.1007/s10964007-9227-x

Roberts, A. L., Austin, S. B., Corliss, H. L., Vandermorris, A. K., $\&$ Koenen, K. C. (2010). Pervasive trauma exposure among US sexual orientation minority adults and risk of posttraumatic stress disorder. American Journal of Public Health, 100(12), 2433-2441. doi:10.2105/AJPH.2009.168971

Roberts, A. L., Gilman, S. E., Breslau, J., Breslau, N., \& Koenen, K. C. (2011). Race/ethnic differences in exposure to traumatic events, development of post-traumatic stress disorder, and treatment-seeking for post-traumatic stress disorder in the United States. Psychological Medicine, 41(1), 71-83. doi:10.1017/S0033291710000401

Sarno, E. L., Mohr, J. J., Jackson, S. D., \& Fassinger, R. E. (2015). When identities collide: Conflicts in allegiances among LGB people of color. Cultural Diversity \& Ethnic Minority Psychology, 21(4), 550-559. doi:10.1037/cdp0000026

Sessa, B. (2017). The 21st century psychedelic renaissance: Heroic steps forward on the back of an elephant. Psychopharmacology, 235(2), 551-560. doi:10.1007/s00213-017-4713-7

Shipherd, J. C., Maguen, S., Skidmore, W. C., \& Abramovitz, S. M. (2011). Potentially traumatic events in a transgender sample: Frequency and associated symptoms. Traumatology, 17(2), 56-67. doi:10.1177/1534765610395614

Straub, K. T., McConnell, A. A., \& Messman-Moore, T. L. (2018). Internalized heterosexism and posttraumatic stress disorder symptoms: The mediating role of shame proneness among trauma-exposed sexual minority women. Psychology of Sexual 
Orientation and Gender Diversity, 5(1), 99-108. doi:10.1037/ sgd0000263

Suite, D. H., La Bril, R., Primm, A., \& Harrison-Ross, P. (2007). Beyond misdiagnosis, misunderstanding and mistrust: Relevance of the historical perspective in the medical and mental health treatment of people of color. Journal of the National Medical Association, 99, 879-885.

United States Drug Enforcement Agency. (2018). Drug scheduling. Retrieved from https://www.dea.gov/drug-scheduling

Williams, M. T. (2018, August 24). Psychedelic psychotherapy is coming: Who will be included? Retrieved from https:// www.psychologytoday.com/us/blog/culturally-speaking/201808/ psychedelic-psychotherapy-is-coming-who-will-be-included

Williams, M. T., Jayawickreme, N., Sposato, R., \& Foa, E. B. (2012). Race-specific associations between trauma cognitions and symptoms of alcohol dependence in individuals with comorbid PTSD and alcohol dependence. Addictive Behaviors, 37(1), 47-52. doi:10.1016/j.addbeh.2011.08.008

Williams, M. T., Kanter, J. W., \& Ching, T. H. W. (2018). Anxiety, stress, and trauma symptoms in African Americans: Negative affectivity does not explain the relationship between microaggressions and psychopathology. Journal of Racial and Ethnic Health Disparities, 5(5), 919-927. doi:10.1007/s40615017-0440-3
Williams, M. T., \& Leins, C. (2016). Race-based trauma: The challenge and promise of MDMA-assisted psychotherapy. MAPS Bulletin, 26, 32-37.

Williams, M. T., Malcoun, E., Sawyer, B., Davis, D. M., BahojbNouri, L. V., \& Leavell, B. S. (2014). Cultural adaptations of prolonged exposure therapy for treatment and prevention of posttraumatic stress disorder in African Americans. Behavioral Sciences, 4(2), 102-124. doi:10.3390/bs4020102

Williams, M. T., Peña, A., \& Mier-Chairez, J. (2017). Assessing and treating racism-related stress and trauma among Latinos. In L. T. Benuto (Ed.), Toolkit for counseling Spanish-speaking clients: Enhancing behavioral health services (pp. 71-96). New York, NY: Springer.

Williams, M. T., Reed, S. R., \& Aggarwal, R. (in press). Culturally informed research design issues in a study for MDMA-assisted psychotherapy for posttraumatic stress disorder. Journal of Psychedelic Studies.

World Health Organization. (2019, April 1). HA60 gender incongruence of adolescence or adulthood. Retrieved from https://icd. who.int/browse11/1-m/en\#/http://id.who.int/icd/entity/90875286

Yang, L. H., \& Kleinman, A. (2008). 'Face' and the embodiment of stigma in China: The cases of schizophrenia and AIDS. Social Science \& Medicine, 67(3), 398-408. doi:10.1016/j. socscimed.2008.03.011 